\title{
Buchwald-Hartwig Amination Using Pd(I) Dimer Precatalysts Supported by Biaryl Phosphine Ligands
}

\author{
Kent O. Kirlikovali, ${ }^{\mathrm{a}}$ Eunho Cho, ${ }^{\mathrm{a}}$ Tyler J. Downard, ${ }^{\mathrm{a}}$ Lilit Grigoryan, ${ }^{\mathrm{a}}$ Zheng Han, ${ }^{\mathrm{a}}$ Sooji Hong, ${ }^{\mathrm{a}}$ \\ Dahee Jung, Jason C. Quintana, ${ }^{a}$ Vanessa Reynoso, ${ }^{a}$ Sooihk Ro, ${ }^{a}$ Yi Shen, ${ }^{a}$ Kevin Swartz, ${ }^{a}$ Elizabeth \\ Ter Sahakyan, ${ }^{a}$ Alex I. Wixtrom, ${ }^{a}$ Brandon Yoshida, ${ }^{a}$ Arnold L. Rheingold, ${ }^{b}$ Alexander M. \\ Spokoyny*a,c
}

We report the synthesis of air-stable $\mathrm{Pd}(\mathrm{I})$ dimer complexes featuring biaryl phosphine ligands. Catalytic experiments suggest that these complexes are comptent precatalysts that can mediate cross-coupling amination reactions between aryl halide electrophiles with both aliphatic and aromatic amine nucleophiles. This work represents an expansion of the air-stable precatalyst toolbox for Pd-catalyzed cross-coupling transformations.

Palladium-catalyzed cross-coupling reactions are ubiquitous synthetic tools, providing practitioners with versatile methods to forge carbon-carbon ${ }^{1}$ and carbonheteroatom ${ }^{2}$ bonds. The development of air- and moisturestable $\mathrm{Pd}(\mathrm{II})$ precatalysts that can quickly generate the catalytically active $\mathrm{Pd}(0)$ species in situ has dramatically improved the scope of transformations and increased the efficiency of these reactions when compared to systems that incorporate traditional palladium sources. ${ }^{3}$ Typically, $\mathrm{Pd}(\mathrm{II})$ precatalysts are activated by an external base followed by a reductive elimination to form the catalytically active $\mathrm{Pd}(0)$ species and an organic-based auxiliary (e.g., carbazole, ${ }^{3 a-c}$ pyridine, $^{3 \mathrm{~d}-\mathrm{f}}$ allylic ethers, ${ }^{3 \mathrm{~g}, \mathrm{~h}}$ and benzylamines ${ }^{3 \mathrm{i}}$ ) as a side product. A Pd-based precatalyst that does not require external base or form side products would result in fewer by-products formed en route to the catalytically active $\mathrm{Pd}(0)$ species and overall greater operational simplicity.

A lesser-studied class of air-stable, dinuclear $\mathrm{Pd}(\mathrm{I})$ complexes have previously shown promise as precatalysts for cross-coupling reactions (Fig 1 ). ${ }^{4-8}$ In contrast to base-activated $\mathrm{Pd}(\mathrm{II})$ precatalysts, $\mathrm{Pd}(\mathrm{I})$ dimer precatalysts are thought to either disproportionate to yield both $\mathrm{Pd}(0)$ and $\mathrm{Pd}(\mathrm{II})$ species upon thermal activation, or form $\operatorname{Pd}(0)$ after reduction from nucleophile or base that are also present in the reaction

\footnotetext{
a. Department of Chemistry and Biochemistry, University of California, Los Angeles, 607 Charles E. Young Drive East, Los Angeles, California 90095, United States

${ }^{b .}$ Department of Chemistry, University of California, San Diego, 9500 Gilman Drive, La Jolla, California 92093, United States

California NanoSystems Institute (CNSI), University of California, Los Angeles, 570 Westwood Plaza, Los Angeles, California 90095, United States

+ This work was completed as a part of an advanced inorganic/organometallic chemistry undergraduate laboratory course (Chemistry 174) taught at UCLA during the Winter of 2017.

Electronic Supplementary Information (ESI) available: Full experimental procedures, multinuclear NMR data, and CIFs.
}

mixture. ${ }^{4 a}$ Following the initial report of halide-bridged $\mathrm{Pd}(\mathrm{I})$ dimers $\mathrm{Pd}_{2}(\mu-\mathrm{X})_{2}\left(\mathrm{P}^{t} \mathrm{Bu}_{3}\right)_{2}(\mathrm{X}=\mathrm{Br}, \mathrm{I})$ in 1996 (Fig. 1), ${ }^{5}$ Hartwig and coworkers showed that these complexes were effective precatalysts for both $\mathrm{C}-\mathrm{C}$ and $\mathrm{C}-\mathrm{N}$ cross-coupling reactions. ${ }^{6}$ More recently, Schoenebeck and colleagues have developed conditions for this precatalyst system that are capable of chemoselective transformations with a wider breadth of substrates. $^{7}$

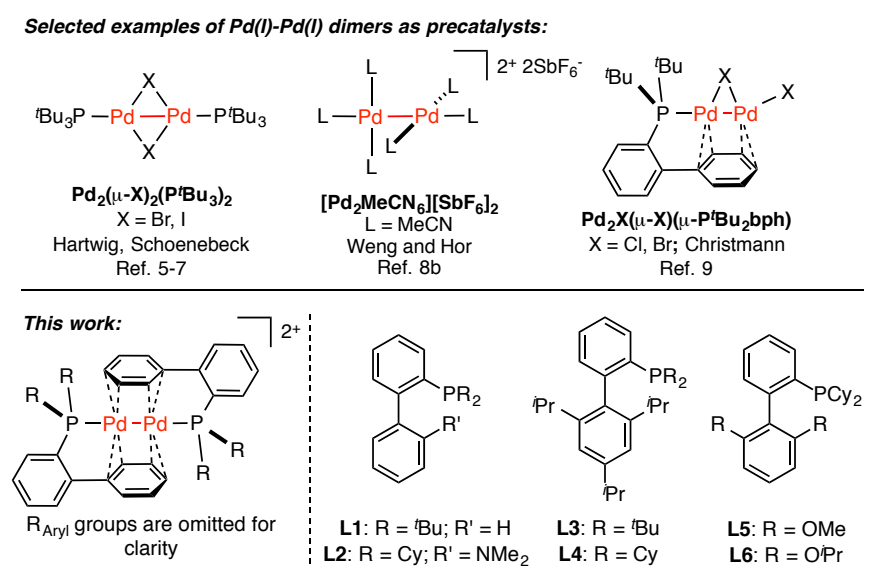

Fig. 1 Top: selected examples of $\mathrm{Pd}(\mathrm{I})$ dimer complexes as precatalysts. Bottom: $\mathrm{Pd}(\mathrm{I})$ dimers synthesized in this work with biaryl phosphine ligands used (L1-L6).

In contrast to the halide-bridged $\mathrm{Pd}(\mathrm{I})$ dimer complex, Murahashi et al. reported the first homoleptic dinucelar $\mathrm{Pd}(\mathrm{I})$ complex $\left[\mathrm{Pd}_{2} \mathrm{MeCN}_{6}\right]\left[\mathrm{BF}_{4}\right]_{2}$ that features a direct $\mathrm{Pd}-\mathrm{Pd}$ interaction with no bridging ligands. ${ }^{8 a}$ Hor and coworkers then demonstrated that the $\left[\mathrm{SbF}_{6}\right]$ analogue of this dimer, $\left[\mathrm{Pd}_{2} \mathrm{MeCN}_{6}\right]\left[\mathrm{SbF}_{6}\right]_{2}$, was an active "ligandless" precatalyst for Suzuki-Miyaura cross-coupling reactions (Fig. 1). ${ }^{8 \mathrm{~b}}$ In fact, the addition of phosphine ligands was found to enhance catalytic performance, though no phosphine-ligated Pd complexes were isolated in this study. Biaryl phosphine ligands have been shown to improve reactivity and expand the substrate scope for many Pd-based catalytic transformations. ${ }^{9,1 f, 2 a-d, 3 a-c}$ Based on this reasoning, Christmann and colleagues went on to synthesize a $\mathrm{Pd}(\mathrm{I})$ dimer that incorporated a bulky biaryl phosphine, $\mathrm{Pd}_{2} \mathrm{X}(\mu-\mathrm{X})\left(\mu-\mathrm{P}^{t} \mathrm{Bu} \mathrm{u}_{2} \mathrm{bph}\right)(\mathrm{X}=\mathrm{Cl}, \mathrm{Br}$; Fig. 1$){ }^{10}$ These $\mathrm{Pd}(\mathrm{I})$ dimers were effective precatalysts for amination reactions of aryl halides; however, the synthesis of these 
dimers is lengthy (48 $\mathrm{hr}$ reaction time), low-yielding (45-71\%), and not general as only one type of biaryl phosphine ligand was used. Similarly, a $\operatorname{Pd}(\mathrm{I})$ dimer supported by two biaryl phosphine ligands was reported by Barder and showed promise as a precatalyst for $\mathrm{C}-\mathrm{C}$ bond-forming reactions, but again, the reported synthesis was not general for other analogous $\mathrm{Pd}(\mathrm{I})$ dimer complexes. ${ }^{11}$

We were interested in expanding the class of $\mathrm{Pd}(\mathrm{I})$ dimers with biaryl phosphine ligands and studying their performance as precatalysts for cross-coupling reactions. To that end, we have developed a straightforward synthetic route that enables access to numerous $\mathrm{Pd}(\mathrm{I})$ dimer complexes via the $\left[\mathrm{Pd}_{2} \mathrm{MeCN}_{6}\right]\left[\mathrm{BF}_{4}\right]_{2}$ precursor. Notably, this method can accommodate several biaryl ligands, and the desired $\operatorname{Pd}(\mathrm{I})$ dimer complexes are formed quantitatively within minutes. These $\mathrm{Pd}(\mathrm{I})$ dimers behave as excellent precatalysts for Buchwald-Hartwig amination reactions, thus expanding the range of available air-stable Pd-based precatalysts.

Following the procedure reported by Murahashi and coworkers, $\left[\mathrm{Pd}_{2} \mathrm{MeCN}_{6}\right]\left[\mathrm{BF}_{4}\right]_{2}$ was synthesized by the conproportionation reaction between $\mathrm{Pd}(0)$ and $\mathrm{Pd}(\mathrm{II})$ $\left(\mathrm{Pd}_{2} \mathrm{dba}_{3}\right.$ and $\left[\mathrm{Pd}(\mathrm{MeCN})_{4}\right]\left[\mathrm{BF}_{4}\right]_{2}$, respectively) on a 0.5 gram scale and served as a competent $\mathrm{Pd}(\mathrm{I})$ dimer precursor (Fig. 2A). To generate $\mathrm{Pd}(\mathrm{I})$ dimer complexes 1-6, two equivalents of a biaryl phosphine ligand (L1-L6) dissolved in $\mathrm{CH}_{2} \mathrm{Cl}_{2}$ were added to a slurry of $\left[\mathrm{Pd}_{2} \mathrm{MeCN}_{6}\right]\left[\mathrm{BF}_{4}\right]_{2}$ in $\mathrm{CH}_{2} \mathrm{Cl}_{2}$ and stirred at room temperature for up to 30 minutes (Fig. 2A). An immediate color change was observed for all reactions, suggesting rapid ligand exchange between biaryl phosphine ligands L1-L6 and acetonitrile. Reaction progress can be easily monitored via $^{31} \mathrm{P}$ NMR as there is a substantial downfield shift upon coordination of the biaryl phosphine ligand to the metal center (Fig. 2B). In some cases, prolonged reaction time results in the formation of Pd-black so shorter reaction times were used to maximize yield ( $<10$ minutes, see ESI for experimental details). This is particularly noticeable in the synthesis of 5: Pdblack forms within minutes of the addition of $\mathbf{L 5}$ to $\left[\mathrm{Pd}_{2} \mathrm{MeCN}_{6}\right]\left[\mathrm{BF}_{4}\right]_{2}$, and the isolated yield of 5 after reacting for 10 minutes is $35 \%$ (the yield increases to $91 \%$ with 1 minute reaction time). In contrast, no $\mathrm{Pd}$-black formation was observed during the synthesis of $\mathbf{6}$, and the isolated yield was quantitative even when the reaction time was 30 minutes. Upon completion, the crude reaction mixtures were filtered through Celite and the filtrates dried in vacuo to offer crystalline solids with yields ranging from $72 \%$ to $99 \%$.

Most compounds exhibit one singlet resonance in the ${ }^{31} \mathrm{P}$ NMR, indicating a symmetric structure and chemically equivalent $P$ atoms. As functional group bulk at the para position on the bottom ring of the biaryl phosphine ligand increases (L3 and L4), multiple ${ }^{31} \mathrm{P}$ NMR resonances are observed. Specifically, two doublets are observed for 4 ( $\delta 39.26$ and $23.15, J_{\mathrm{p}-\mathrm{p}}^{3}=84 \mathrm{~Hz}$, see ESI), suggesting fluctional behavior of the ligand (L4) in solution on the NMR timescale. Steric bulk is increased even more with the replacement of dicyclohexylphosphine (L4) with di-tert-butylphosphine (L3). Indeed, multiple resonances are observed in the ${ }^{31} \mathrm{P} N M R$ spectrum for $\mathbf{3}$, potentially resulting from this increased steric bulk limiting the ability of the ligands to associate with the $\mathrm{Pd}(\mathrm{I})$ centers. Variable temperature (VT) ${ }^{31} \mathrm{P}$ NMR studies on 4 in $\mathrm{CD}_{2} \mathrm{Cl}_{2}$ reveal new resonances at $-80^{\circ} \mathrm{C}$, suggesting the presence of multiple conformations due to limited (or slow) fluctionality at low temperature (Fig. S1). After warming this sample back to $25^{\circ} \mathrm{C}$, the broad resonances reappear, further reinforcing the proposed fluctional behaviour. Due to low solubility and poor stability of $\mathbf{3}$ in $\mathrm{CD}_{2} \mathrm{Cl}_{2}$ solution on the timescale required to acquire ${ }^{31} \mathrm{P} N \mathrm{NMR}$ spectra (vide infra), VT NMR studies were not possible for this sample. Attempts to grow diffraction-quality crystals of $\mathbf{3}$ and $\mathbf{4}$ to validate these suggested structures resulted in the formation of metallic Pd.

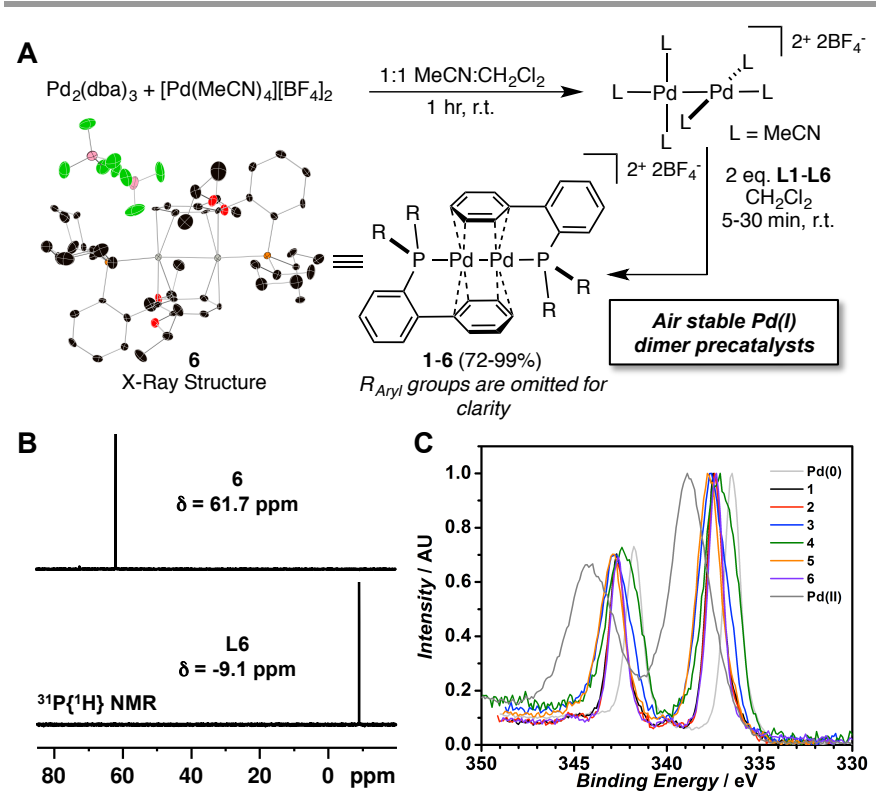

Fig. 2 (A) Synthetic route to $\mathrm{Pd}(\mathrm{I})$ dimer complexes 1-6. Left: X-ray crystal structure of 6 drawn with $50 \%$ ellipsoid probability (CCDC 1812500). $\mathrm{H}$ atoms are omitted for clarity. (B) ${ }^{31} \mathrm{P}\left\{{ }^{1} \mathrm{H}\right\}$ NMR data for $\mathbf{L} 6$ (bottom) and 6 (top), both in $\mathrm{CD}_{2} \mathrm{Cl}_{2}$. (C) XPS data for compounds 1-6. $\operatorname{Pd}(0)$ is $\mathrm{Pd}_{2} \mathrm{dba}_{3}$, and $\operatorname{Pd}(\mathrm{II})$ is $\left[\mathrm{Pd}(\mathrm{MeCN})_{4}\right]\left[\mathrm{BF}_{4}\right]_{2}$.

On the other hand, compounds $\mathbf{2 , 5}$ and $\mathbf{6}$ could all be characterized via single crystal X-ray diffraction, confirming the propsed dimeric structure (Fig. $1 \mathrm{~A}$ and Fig. S2). For all of these dimer structures, $\mathrm{Pd}(\mathrm{I}) \cdots \mathrm{Pd}(\mathrm{I})$ distances range from 2.702$2.716 \AA$ in the solid state, slightly greater than the sum of covalent radii for two Pd atoms (2.40 ̊). ${ }^{12}$ To further probe the oxidation state of Pd in 1-6, we employed X-ray photoelectron spectroscopy (XPS). As anticipated, the binding energies for $\mathrm{Pd}$ $3 d$ electrons in 1-6 fall between the binding energies for $\mathrm{Pd} 3 \mathrm{~d}$ electrons in $\mathrm{Pd}(0) \quad\left(\mathrm{Pd}_{2} \mathrm{dba}_{3}\right)$ and $\mathrm{Pd}(\mathrm{II}) \quad\left(\left[\mathrm{PdMeCN} \mathrm{C}_{4}\right]\left[\mathrm{BF}_{4}\right]_{2}\right)$ standards, suggesting that both $\mathrm{Pd}$ atoms are in the +1 formal oxidation state (Fig. $2 \mathrm{C}$ and Table S2).

Compounds 1-6 are stable as solids indefinitely when stored in air at $5^{\circ} \mathrm{C}$; in contrast, only $\mathbf{5}$ and $\mathbf{6}$ exhibit long-term stability in $\mathrm{CH}_{2} \mathrm{Cl}_{2}$ solution. Solutions of 1-6 in $\mathrm{CH}_{2} \mathrm{Cl}_{2}$ were stored on the bench top under atmospheric conditions, and within 3 days, metallic Pd films coated the vials containing 1-4, whereas 5 and 6 remained in solution with no observed changes in ${ }^{31}$ P NMR spectra after 1 week. Compounds $\mathbf{3}$ and $\mathbf{4}$, which contain ligands with the greatest amount of steric bulk on the bottom aryl ring ( $\mathbf{2} \mathbf{3}$ and $\mathbf{L} \mathbf{4}$, respectively), exhibit the 
lowest stability in $\mathrm{CH}_{2} \mathrm{Cl}_{2}$ solution as Pd-black and metallic $\mathrm{Pd}$ films both start forming within $\mathbf{3 0}$ minutes after dissolution.

We turned our attention to the use of the synthesized $\mathrm{Pd}(\mathrm{I})$ dimers 1-6 as air-stable precatalysts for Buchwald-Hartwig amination reactions. For the initial optimization studies, 4bromotoluene and morpholine were chosen as a reagent system (Table 1 ). We first evaluated 1-6 as precatalysts at 0.5 mol\% loading with 0.5 mol\% corresponding ligand (L1-L6) using $\mathrm{KO}^{t} \mathrm{Bu}$ as the base (entries 1-6). These $\mathrm{Pd}(\mathrm{I})$ dimer complexes are thought to disproportionate to form a Pd(II) species and a catalytically active $\mathrm{Pd}(0)$ species after thermal activation; ${ }^{11}$ therefore, the role of the base in this system is limited to deprotonating the amine adduct of palladium that forms during the transmetallation step.

Table 1 Optimization of reaction conditions for 7 .

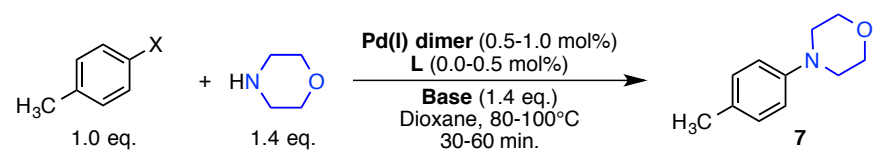

\begin{tabular}{|c|c|c|c|c|c|c|c|}
\hline Entry & $\begin{array}{c}\operatorname{Pd}(\mathrm{I}) \\
\text { Precat. } \\
\text { (mol\%) }\end{array}$ & $\begin{array}{c}\mathbf{L} \\
(\mathrm{mol} \%)\end{array}$ & Base & $x$ & $\begin{array}{c}\text { Temp } \\
\left({ }^{\circ} \mathrm{C}\right)\end{array}$ & $\begin{array}{l}\text { Time } \\
\text { (min.) }\end{array}$ & $\begin{array}{c}\text { Yield }^{a} \\
(\%)\end{array}$ \\
\hline 1 & $1,0.5$ & L1, 0.5 & $\mathrm{KO}^{t} \mathrm{Bu}$ & $\mathrm{Br}$ & 100 & 30 & 46 \\
\hline 2 & $2,0.5$ & L2, 0.5 & $\mathrm{KO}^{t} \mathrm{Bu}$ & $\mathrm{Br}$ & 100 & 30 & 25 \\
\hline 3 & $3,0.5$ & L3, 0.5 & $\mathrm{KO}^{t} \mathrm{Bu}$ & $\mathrm{Br}$ & 100 & 30 & 12 \\
\hline 4 & $4,0.5$ & L4, 0.5 & $\mathrm{KO}^{t} \mathrm{Bu}$ & $\mathrm{Br}$ & 100 & 30 & 45 \\
\hline 5 & $5,0.5$ & L5, 0.5 & $\mathrm{KO}^{t} \mathrm{Bu}$ & $\mathrm{Br}$ & 100 & 30 & 60 \\
\hline 6 & $6,0.5$ & L6, 0.5 & $\mathrm{KO}^{t} \mathrm{Bu}$ & $\mathrm{Br}$ & 100 & 30 & 64 \\
\hline 7 & $6,1.0$ & L6, 0.5 & $\mathrm{KO}^{t} \mathrm{Bu}$ & $\mathrm{Br}$ & 100 & 30 & $>99$ \\
\hline 8 & $6,0.5$ & L6, 0.5 & $\mathrm{KO}^{t} \mathrm{Bu}$ & $\mathrm{Br}$ & 100 & 60 & $>99$ \\
\hline 9 & $6,0.5$ & L6, 0.5 & $\mathrm{KO}^{t} \mathrm{Bu}$ & $\mathrm{Br}$ & 80 & 60 & $>99$ \\
\hline 10 & $6,0.5$ & - & $\mathrm{KO}^{t} \mathrm{Bu}$ & $\mathrm{Br}$ & 80 & 60 & $>99$ \\
\hline 11 & $6,0.5$ & - & $\mathrm{NaO}{ }^{\mathrm{t}} \mathrm{Bu}$ & $\mathrm{Br}$ & 80 & 60 & $>99$ \\
\hline 12 & $6,0.5$ & - & $\mathrm{NaO}{ }^{\mathrm{t}} \mathrm{Bu}$ & $\mathrm{Cl}$ & 80 & 60 & $>99$ \\
\hline 13 & $6,0.5$ & - & $\mathrm{NaO}{ }^{\mathrm{t}} \mathrm{Bu}$ & 1 & 80 & 60 & $40^{b}$ \\
\hline 14 & $5,0.5$ & - & $\mathrm{NaO}^{\mathrm{t}} \mathrm{Bu}$ & $\mathrm{Br}$ & 80 & 60 & $>99$ \\
\hline
\end{tabular}

Pd(I) dimers 1-6 were initially screened to find the most optimal precatalyst. Optimization of the reaction conditions proceeded with $\mathbf{6}$ (optimized conditions in entry 11). ${ }^{a}$ Yield determined using GC-MS analysis. ${ }^{b}$ Full conversion of 4iodotoluene was observed by GC-MS.

After reacting for 30 minutes at $100^{\circ} \mathrm{C}$ in 1,4-dioxane, 5 and 6 offered the highest GC-MS yields of product 7 (60\% and $64 \%$, respectively). Due to the relative ease of synthesis of 6 compared to $\mathbf{5}$ (vide supra), we therefore decided to move forward with 6 as the model $\operatorname{Pd}(I)$ dimer precatalyst. Full conversion of 4-bromotoluene was achieved both when the precatalyst loading was doubled to 1.0 mol\% (entry 7) and when the reaction time was increased to 1 hour (entry 8), demonstrating that increasing the catalyst loading was not necessary as lower catalyst loadings with longer reaction times were sufficient for full conversion. The temperature was decreased from $100^{\circ} \mathrm{C}$ to $80^{\circ} \mathrm{C}$ during the subsequent optimization with no observed yield, and inclusion of extra supporting ligand $\mathbf{L} 6$ was deemed unnecessary (entries 9 and 10 , respectively). $\mathrm{NaO}^{t} \mathrm{Bu}$ was successfully substituted for $\mathrm{KO}^{t} \mathrm{Bu}$ as the yield remained $>99 \%$ for this experiment (entry
11). No significant change in performance was observed when varying the halide from bromide to chloride (entry 12), but there was a precipitous drop in the observed yield when 4iodotoluene was employed (entry 13). This is consistent with previously observed trends in Pd-catalyzed cross-coupling with systems featuring electron-rich biaryl ligands where transmetallation is a rate-determining step. ${ }^{13}$ Finally, the use of precatalyst $\mathbf{5}$ under the optimized conditions still results in GC-MS yields $>99 \%$ (entry 14 ).

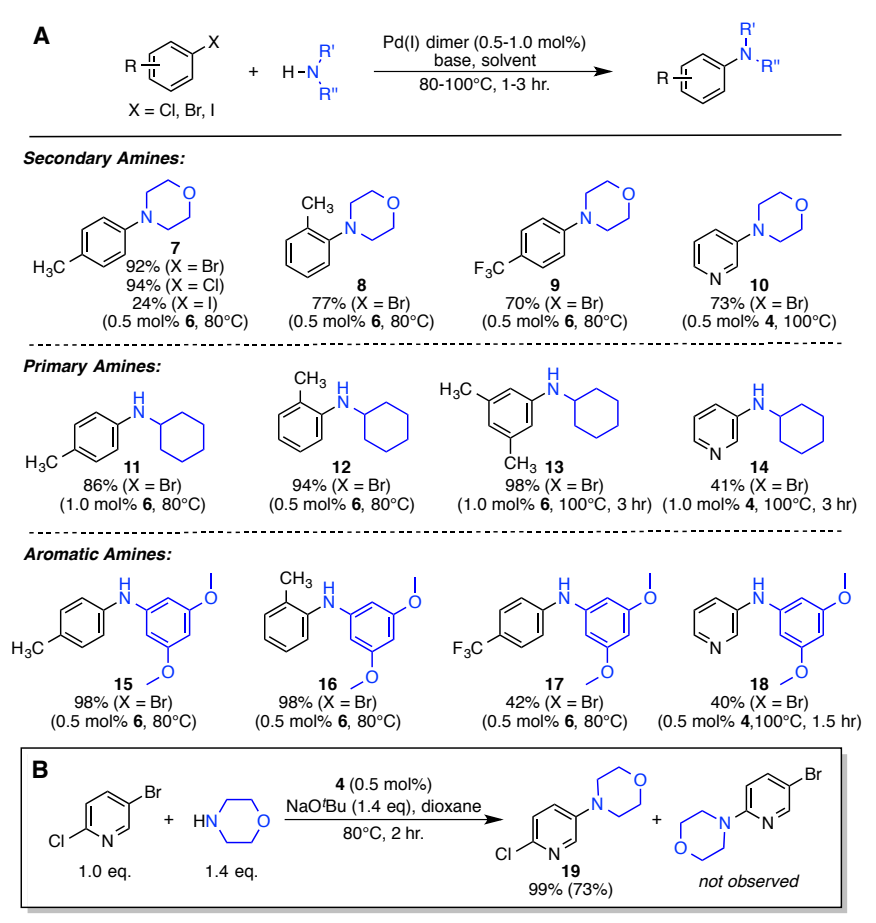

Fig. 3 (A) Substrate scope for the amination of aryl and heterocyclic halides. Conditions: Aryl halide $(2.5 \mathrm{mmol})$, amine $(3.5 \mathrm{mmol}), \mathrm{NaO}{ }^{t} \mathrm{Bu}(3.5 \mathrm{mmol}), \mathrm{Pd}(\mathrm{I})$ dimer precatalyst (0.5-1.0 mol\%), dioxane $(2.5 \mathrm{~mL}), 80-100^{\circ} \mathrm{C}, 1-3 \mathrm{hr}$. Isolated yields represent the average of two runs. (B) Amination of a mixed-halide heterocycle demonstrates selectivity for bromide (99\% conversion of 5 -bromo-2-chloropyridine, $73 \%$ isolated yield or 19).

The optimized conditions presented in entry 11 were adopted for further experiments to expand the substrate scope. Precatalyst 6 was found to work with a range of aryl bromides and multiple types of nucleophiles, including secondary amines (7-10), primary amines (11-14), and aromatic amines (15-18, Fig. 3A). Reactions between 4bromotoluene and both cyclohexylamine and 3,5dimethoxyaniline (7 and $\mathbf{1 1}$, respectively) proceeded with 0.5 1.0 mol\% loading of 6 . Using this catalytic system, aryl bromides with electron-withdrawing trifluoromethyl groups in the para-position were found to work with secondary amines and anilines $(9,17)$. Reactions with ortho-substituted aryl bromides proceeded efficiently with all three classes of amines, and products were isolated in yields of up to $98 \%(8$, 12, 16). In all cases, reactions involving a heterocyclic electrophile (3-bromopyridine) proceeded sluggishly with GCMS yields $<30 \%$ when the standard reaction conditions were employed with 6 as a precatalyst. However, precatalyst 4 proved competent for the transformation between all three 
classes of amines and 3-bromopyridine $(10,14,18)$, demonstrating the potential utility of this class of $\operatorname{Pd}(\mathrm{I})$ dimer precatalysts. This observation is consistent with previous reports that suggest the increased bulk of $\mathbf{L} \mathbf{4}$ leads to greater efficiency of aminations of heteroaryl halides. ${ }^{2 \mathrm{a}, 9 \mathrm{~g}}$

Finally, a reaction between morpholine and a 2-chloro-5bromopyridine was performed to test halide selectivity and confirm that this transformation proceeds via cross-coupling and not through an aromatic nucleophilic substitution $\left(S_{N} A r\right)$ pathway (Fig. 3B). Full conversion of the electrophile was achieved after 2 hours, but no chloro-substituted product could be detected by GC-MS. In fact, only the desired product (19) was observed by GC-MS and isolated yield in $73 \%$ yield, confirming the selectivity of this class of precatalysts for bromide. Moreover, this selectivity potentially enables the use of orthogonal methods that are reactive towards chlorides, ${ }^{14}$ enhancing the prospective scope of transformations available with this precatalyst system.

In conclusion, we have synthesized and characterized a series of air-stable $\mathrm{Pd}(\mathrm{I})$ dimer complexes incorporating biaryl phosphine ligands. A conproportionation reaction between commercially-available $\mathrm{Pd}(0)$ and $\mathrm{Pd}(\mathrm{II})$ sources followed by the addition of biaryl phosphine ligands results in a nearly quantitative strategy towards the synthesis of these complexes. Single crystal $\mathrm{X}$-ray diffraction studies on several $\mathrm{Pd}(\mathrm{I})$ dimers supported by the biaryl phosphine ligands confirm the proposed dimeric structure of these complexes in the solid state, and XPS data suggests the +1 formal oxidation state of the $\mathrm{Pd}$ atoms in each dimer complex. Synthesized $\mathrm{Pd}(\mathrm{I})$ dimers can efficiently catalyze Buchwald-Hartwig amination reactions involving aliphatic or aromatic amines with aryl halides, including 6-membered heterocyclic substrates. Overall, this work presents a direct and simple route to a potentially large class of air-stable $\mathrm{Pd}(\mathrm{I})$ dimer precatalysts which, by further tailoring the biaryl phosphine ligand, can be used for other cross-coupling transformations.

\section{Conflicts of interest}

There are no conflicts to declare.

\section{Notes and references}

1 (a) R. F. Heck, J. P. Nolley, Jr., J. Org. Chem., 1972, 37, 23202322; (b) M. Kumada, Pure \& Appl. Chem., 1980, 52, 669679; (c) E. Negishi, A. O. King, N. Okukado, J. Org. Chem., 1977, 42, 1821-1823; (d) N. Miyaura, A. Suzuki, Chem. Rev., 1995, 95, 2457-2483; (e) J. K. Stille, Angew. Chem. Int. Ed., 1986, 25, 508-524; (f) R. Martin, S. L. Buchwald, Acc. Chem. Res., 2008, 41, 1461-1473.

2 (a) D. Surry, S. L. Buchwald, Angew. Chem. Int. Ed., 2008, 47, 6338-6361; (b) P. Ruiz-Castillo, S. L. Buchwald, Chem. Rev., 2016, 116, 12564-12649; (c) A. C. Sather, S. L. Buchwald, Acc. Chem. Res., 2016, 49, 2146-2157; (d) G. D. Vo, J. F. Hartwig, J. Am. Chem. Soc., 2009, 131, 11049-11061; (e) M. A. Fernández-Rodríguez, J. F. Hartwig, Chem. Eur. J., 2010, 16, 2355-2359; (f) A. T. Brusoe, J. F. Hartwig, J. Am. Chem. Soc., 2015, 137, 8460-8468.
3 (a) N. C. Bruno, M. T. Tudge, S. L. Buchwald, Chem. Sci. 2013, 4, 916-920; (b) N. C. Bruno, S. L. Buchwald, Org. Lett., 2013, 15, 2876-2879; (c) N. C. Bruno, N. Niljianskul, S. L. Buchwald, J. Org. Chem., 2014, 79, 4161-4166; (d) C. J. O'brien, E. A. B. Kantchev, C. Valente, N. Hadei, G. A. Chass, A. Lough, A. C. Hopkinson, M. G. Organ, Chem. Eur. J., 2006, 12, 4743-4748; (e) M. G. Organ, S. Avola, I. Dubovyk, N. Hadei, E. A. B. Kantchev, C. J. O'brien, C. Valente, Chem. Eur. J., 2006, 12, 4749-4755; (f) M. G. Organ, S. Çalimsiz, M. Sayah, K. H. Hoi, and A. J. Lough, Angew. Chem. Int. Ed., 2009, 48, 2383-2387; (g) M. S. Viciu, R. F. Germaneau, O. Navarro-Fernandez, E. D. Stevens, S. P. Nolan, Organometallics, 2002, 21, 5470-5472; (h) N. Marion, O. Navarro, J. Mei, E. D. Stevens, N. M. Scott, S. P. Nolan, J. Am. Chem. Soc., 2006, 128, 4101-4111; (i) R. B. Bedford, C. S. J. Cazin, S. J. Coles, T. Gelbrich, P. N. Horton, M. B. Hursthouse, M. E. Light, Organometallics, 2003, 22, 987-999; (j) N. Marion, S. P. Nolan, Acc. Chem. Res., 2008, 41, 1440-1449; (k) U. Christmann, R. Vilar, Angew. Chem. Int. Ed., 2005, 44, 366-374.

4 (a) I. G. Powers, C. Uyeda, ACS Catal., 2017, 7, 936-958; (b) N. Hazari, D. P. Hruszkewycz, Chem. Soc. Rev., 2016, 45, 2871-2899; (c) R. S. Paton, J. M. Brown, Angew. Chem. Int. Ed., 2012, 51, 10448-10450; (d) S. Lin, D. E. Herbert, A. Velian, M. W. Day, T. Agapie, J. Am. Chem. Soc., 2013, 135, 15830-15840.

5 R. Vilar, D. M. P. Mingos, C. J. Cardin, J. Chem. Soc., Dalton Trans., 1996, 4313-4314.

6 J. P. Stambuli, R. Kuwano, J. F. Hartwig, Angew. Chem. Int. Ed., 2002, 41, 4746-4748.

7 (a) M. Aufiero, T. Scattolin, F. Proutière, F. Schoenebeck, Organometallics, 2015, 34, 5191-5195; (b) T. Sperger, C. K. Stirner, F. Schoenebeck, Synthesis, 2017, 49, 115-120; (c) I. Kalvet, T. Sperger, T. Scattolin, G. Magnin, F. Schoenebeck, Angew. Chem. Int. Ed., 2017, 56, 7078-7082; (d) I. Kalvet, G. Magnin, F. Schoenebeck, Angew. Chem. Int. Ed., 2017, 56, 1581-1585.

8 (a) T. Murahashi, T. Nagai, T. Okuno, T. Matsutani, H. Kurosawa, Chem. Commun., 2000, 1689-1690; (b) X. Han, Z. Weng, T. S. A. Hor, J. Organomet. Chem., 2007, 692, 56905696.

9 (a) E. Jacobsen, Adv. Synth. Catal., 2015, 357, 2173-2174; (b) E. R. Strieter, D. G. Blackmond, S. L. Buchwald, J. Am. Chem. Soc., 2003, 125, 13978-13980; (c) U. Christmann, R. Vilar, Angew. Chem. Int. Ed., 2005, 44, 366-374; (d) V. Farina, Adv. Synth. Catal., 2004, 346, 1553-1582; (e) E. R. Strieter, S. L. Buchwald, Angew. Chem. Int. Ed., 2006, 45, 925-928; (f) C. W. Cheung, D. S. Surry, S. L. Buchwald, Org. Lett., 2013, 15, 3734-3737.; (g) K. W. Anderson, R. E. Tundel, T. Ikawa, R. A. Altman, S. L. Buchwald, Angew. Chem. Int. Ed., 2006, 45, 6523-6527.

10 U. Christmann, R. Vilar, A. J. P. White, D. J. Williams, Chem. Commun., 2004, 1294-1295.

11 T. E. Barder, J. Am. Chem. Soc., 2006, 128, 898-904.

12 P. Pyykkö, M. Atsumi, Chem. Eur. J., 2009, 15, 186-197.

13 (a) L. Salvi, N. R. Davis, S. Z. Ali, S. L. Buchwald, Org. Lett., 2012, 14, 170-173; (b) S. D. Friis, T. Skrydstrup, S. L. Buchwald, Org. Lett., 2014, 16, 4296-4299; (c) A. H. Roy, J. F. Hartwig, Organometallics, 2004, 23, 1533-1541; (d) T. D. Sheppard, Org. Biomol. Chem., 2009, 7, 1043-1052.

14 M. H. Keylor, Z. L. Niemeyer, M. S. Sigman, K. L. Tan, J. Am. Chem. Soc., 2017, 139, 10613-10616. 